ORIGINAL PAPER

\title{
CONGENITAL CYSTIC ADENOMATOID MALFORMATION PRESENTATION OF 11 CASES AND LITERATURE REVIEW
}

\author{
Józef Kobos ${ }^{1}$, Damian Meynarski ${ }^{2}$, Bartosz Bogusz ${ }^{3}$, Wojciech Górecki ${ }^{3}$
}

\begin{abstract}
${ }^{1}$ Department of Histology and Embryology, Chair of Anatomy and Histology, Medical University of Lodz, Poland ${ }^{2}$ Department of Pathology, University Children's Hospital of Krakow, Poland ${ }^{3}$ Department of Pediatric Surgery, Jagiellonian University Medical College, University Children's Hospital of Krakow, Poland
\end{abstract}

\begin{abstract}
The aim of the study was to present cases of congenital cystic adenomatoid malformation (CCAM) in terms of pathological features, gender and site distribution as well as to compare the results with Stocker's classification.

A retrospective review was performed on eleven cases of CCAM obtained in 4-years period (2015-2019) in University Children's Hospital in Krakow, in Poland.

The cases for this study were 7 boys and 4 girls (64\% vs. 36\%). Patients age at surgery ranged from 4 days to 10 months. 6 cases involved the left lung (55\%) whereas the right lung was involved in 5 cases (45\%). Histopathological examination showed congenital cystic adenomatoid malformation type I in 7 cases (64\%), type II in 3 cases $(27 \%)$ and type III in 1 case (9\%). No congenital cystic adenomatoid malformation type 0 nor IV was diagnosed.

Data obtained from this study correspond to Stocker's classification, showing that the most common CCAM types are those associated with good prognosis. Histopathological features should always confirm the nature of the lesion, that is initially suspected in the imaging examination.
\end{abstract}

Key words: congenital cystic adenomatoid malformation, CCAM, lung lesion, respiratory tract disorder.

\section{Introduction}

Congenital cystic adenomatoid malformation (CCAM) is a rare respiratory tract disorder that can lead to serious clinical problems, arising in approximately 1 in 30000 live births which manifests in a lung as a single or multiple, cystic or adenomatoid lesion of various size. It may involve a single lobe or a whole lung and it may coexist with other pulmonary defects but is often an isolated lesion. Its pathogenesis is still not clear and it may regress spontanously. It is often diagnosed accidentally during pregnancy on ultrasound examinations. It can be classified into one of five groups ( 0 to IV) according to Stocker's classification system (Table I), type I being the most frequent and type 0 the rarest one [1]. This study presents and compares cases of CCAM obtained from eleven patients.

\section{Material and methods}

Our eleven cases were obtained in a 4-years period (2015-2019) in University Children's Hospital in Krakow, Poland. We took into consideration data such as age at which the patient was operated, gender, location of congenital cystic adenomatoid malformation (right vs. left lung), macroscopic appearance (which sometimes may lead to initial suspicion 
of the type of CCAM), clinical diagnosis (based on medical imaging techniques) and additional lesions that were present in the lungs apart from the congenital cystic adenomatoid malformation. The aim was to compare those eleven cases in terms of above-mentioned criteria and to present their histological appearance according to Stocker's classification system [1].

\section{Results}

The cases for this study concerned 11 patients ( 7 boys, 4 girls, $64 \%$ vs. $36 \%$ ) who were hospitalized in Universal Children's Hospital in Krakow in 20152019. The congenital cystic adenomatoid transformation (or the suspicion of) was clinically diagnosed in 9 cases, 2 cases were clinically diagnosed as either congenital sequestration of the lung or a cystic lesion of the lung (without exact specification). Patients age at surgery ranged from 4 days to 10 months. 6 cases involved the left lung (55\%) whereas the right lung was involved in 5 cases (45\%). There was a slight predilection for congenital cystic adenomatoid malformation to arise in the left lung ( 4 cases, $57 \%$ ) rather in the right lung (3 cases, $43 \%$ ) in male patients. In female patients the right and left lung distribution of congenital cystic adenomatoid malformation was even ( 2 cases, $50 \%$ for both right and left lung).

Total resection of the lung (right one) was performed in 1 case $(9 \%)$, while lobectomy was performed in 10 cases $(91 \%)$. Lobectomy involved resection of the lower lobe in 7 cases $(70 \%)$, the middle lobe in 1 case (10\%), the upper lobe in 1 case $(10 \%)$ and the upper and the middle lobe combined in 1 case $(10 \%)$.

Macroscopically the changes ranged from focal cystic lesions up to $0.8 \mathrm{~cm}$ in diameter to single cystic lesions up to $4 \mathrm{~cm}$ in diameter. Additional specimens (apart from the specimen with the main lesion) that were obtained for histopathological examination in those cases included:

- a part of ligamentum pulmonale (histologically: with blood effusions),

- single lymph node (histologically: with non-specific reactive changes),
- small parts of fibrin-like material from the pleura of the middle and upper lobe (histologically: parts of fibrous connective tissue with foci of non-specific granulation tissue, mixed-cell inflammation and fibrin).

There were coexisting changes/features that were observed histopathologically in the remaining part of specimens such as: focal atelectasis in 9 cases $(81 \%)$, focal emphysema in 10 cases $(90 \%)$, intra-alveolar effusions in all cases $(100 \%)$, focal oedema in 7 cases $(64 \%)$, non-specific granulation tissue in 2 cases (18\%), hemosiderin-laden macrophages in 7 cases $(64 \%)$, foamy macrophages in 4 cases $(36 \%)$ and foci of inflammation in 2 cases (18\%). The focal inflammation observed in 2 cases presented as either dispersed catarrhal-purulent inflammation or a focal scant mixed-cell inflammation. No malignant changes were observed histologically in any of the specimens.

Histopathological examination showed congenital cystic adenomatoid malformation type $I$ in 7 cases (64\%), type II in 3 cases (27\%) and type III in 1 case (9\%). No congenital cystic adenomatoid malformation type 0 and IV was diagnosed.

Microscopically lesions diagnosed as CCAM type I revealed large cysts lined with ciliated pseudostratified epithelium with foci of mucus cells and cartilage, CCAM type II showed numerous small cysts lined with columnar and partially cuboidal epithelium, and CCAM type III revealed numerous small cysts lined with "plump" cuboidal epithelium.

In our studies congenital cystic adenomatoid malformation type I involved the right lung in 3 cases $(42 \%)$ and left lung in 4 cases $(58 \%)$ and could be found in 1 case in the specimen obtained in total resection of the lung (14\%), in the specimens from lower lobe lobectomy in 4 cases $(58 \%)$, in the specimen from middle lobe lobectomy in 1 case (14\%) and in the specimen from the upper lobe lobectomy in 1 case (14\%). Congenital cystic adenomatoid malformation type II involved the right lung in 1 case $(33 \%)$ and left lung in 2 cases $(67 \%)$, and it could be found in 3 cases of lower lobe lobectomy (100\%).

Table I. Macro- and microscopic features of CCAM types

\begin{tabular}{|c|c|}
\hline TyPe 0 & $\begin{array}{c}\text { Small, firm lungs, microscopically with bronchus-like structures, numerous cartilage plates, prognosis: } \\
\text { lethal condition }\end{array}$ \\
\hline TyPe I & $\begin{array}{l}\text { Large cysts up to } 10 \mathrm{~cm} \text { in diameter (one may be dominant), microscopically lined with ciliated } \\
\text { pseudostratified cells, mucus cells and cartilage may be present, prognosis: good }\end{array}$ \\
\hline TYPE II & $\begin{array}{c}\text { Small cysts up to } 2 \mathrm{~cm} \text { in diameter, lined with cuboidal or columnar ciliated epithelium, may have solid } \\
\text { areas, prognosis: poor }\end{array}$ \\
\hline Type III & $\begin{array}{l}\text { Solid gross appearance, small air spaces lined with cuboidal epithelium, prognosis: poor (depends on } \\
\text { the extent of the lesion) }\end{array}$ \\
\hline TyPE IV & $\begin{array}{c}\text { Large cysts up to } 10 \mathrm{~cm} \text { in diameter, lined with flattened epithelium, prognosis: good (differential } \\
\text { diagnosis should always involve pleuropulmonary blastoma) }\end{array}$ \\
\hline
\end{tabular}



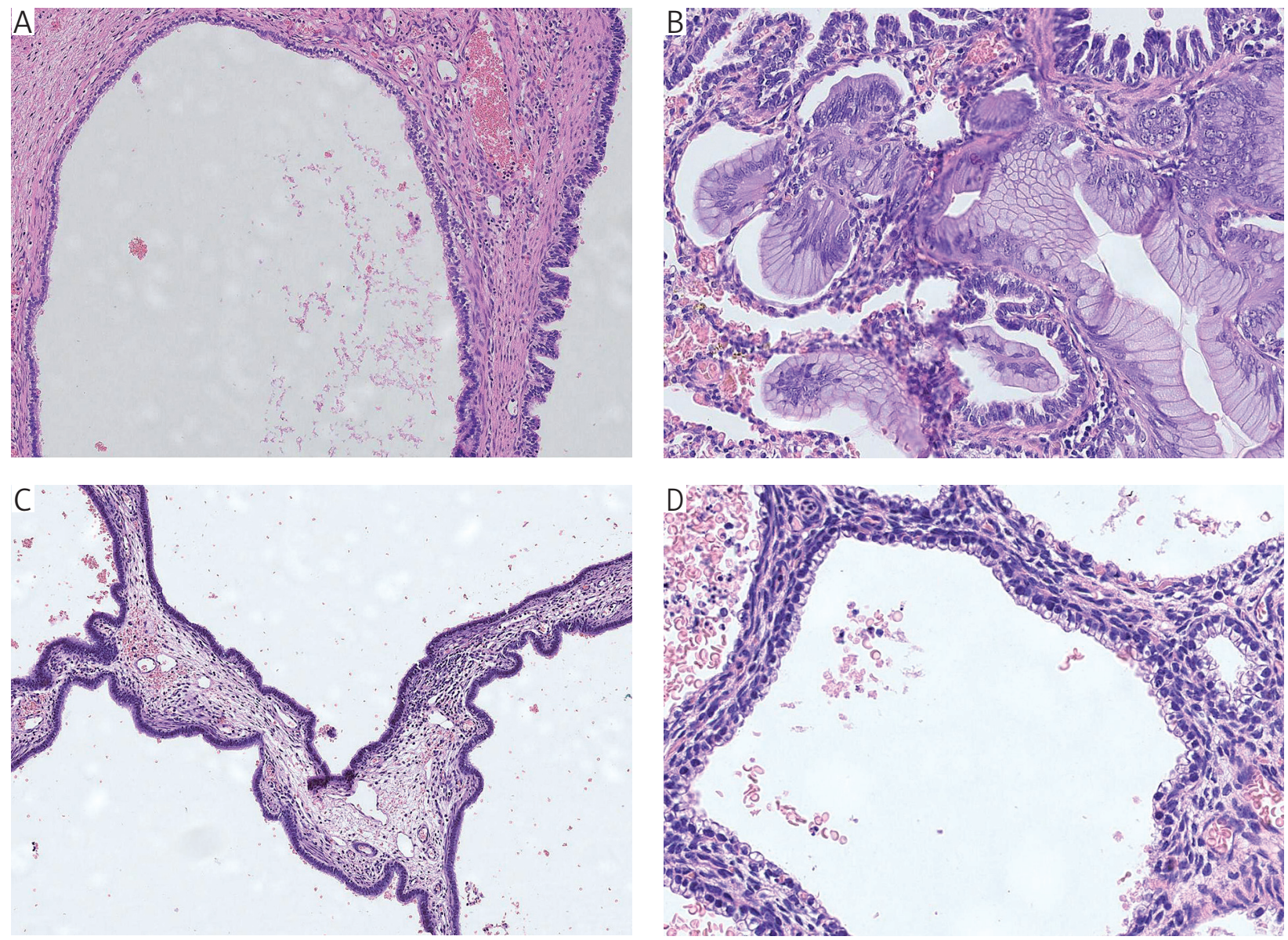

Fig. 1. A) CCAM type I, fragment of a large cyst wall lined with a ciliated columnar epithelium partially with "ruffled" appearance $(\mathrm{HE}$, magnification $30 \times$ ). B) CCAM type I, mucogenic cells in the wall of the cyst (HE, magnification $20 \times$ ). C) CCAM type II, cyst walls with scant amount of connective tissue lined with cuboid and columnar epithelium (HE, magnification $20 \times$ ). D) CCAM type III, small air spaces separated by thin walls lined with cuboidal "plump" epithelium, no mucogenic cells or cartilage (HE, magnification $40 \times$ )

Congenital cystic adenomatoid malformation type III involved the right lung in 1 case $(100 \%)$ and was found in the specimen from upper and middle lobe lobectomy.

Gender-wise congenital cystic adenomatoid malformation type I was present in male patients in 5 cases $(72 \%)$, type II in 1 case $(14 \%)$, and type III in 1 case $(14 \%)$ whereas in female patients type I was present in 2 cases $(50 \%)$ and type II also in 2 cases (50\%) (Fig. 1).

\section{Discussion}

Congenital cystic adenomatoid malformation was first described in 1949 by Ch'In and Tang. This entity is a developmental anomaly localized in lungs (one or both). The incidence is 1 in 30000 live births but its frequency is believed to be rising [2]. The pathogenesis is not fully understood nor totally clearly explained but molecular studies show a group of different genes expressed in those anomalies [3]. Congenital cystic adenomatoid malformation may be a life-threatening condition [4] or it may undergo regression. Although CCAMs are congenital they can be asymptomatic $[5,6]$ and be detected later in life $[7,8]$. Malignant transformation within CCAM is not frequent but may occur at any age [9]. Congenital cystic adenomatoid malformation is a part of a spectrum of congenital pulmonary lesions that also include pulmonary sequestrations, bronchogenic cysts, and congenital lobar emphysema [10, 11, 12]. The vast majority of congenital cystic adenomatoid malformations are diagnosed by fetal ultrasonography with additional MRI and CT postnatally and the surgery is the fundamental treatment of symptomatic CCAMs [13].

The cases in our studies concerned 11 patients aged from 4 days to 10 months. The histological presentation of the lesions was rather typical. Histologically CCAM is divided into five types; the origin of those types is also widely distributed in the anatomical structures in the lungs. Type 0 is of tracheal or bronchial, type I of bronchial or bronchiolar, type II of bronchiolar, type III of bronchiolar-alveolar 
and type IV of distal acinar origin. Among all types CCAM type I is by far the most frequent, comprising about $60 \%$ to $70 \%$ of the cases, followed by type II (10-15\%), type IV (15\%), type III (5\%) and type 0 (1-3\%). Our study reflects those proportions in cases of CCAM type I, II and III. No type 0 or IV was diagnosed which is probably due to the relatively low count of cases.

In conclusion, congenital cystic adenomatoid malformation is a disorder in the genesis of the respiratory tract that manifests itself as a one of five different types with distinct macroscopical and histological features. They can be associated with good or poor prognosis and one of the types (type 0 , the rarest one) is associated with a fatal outcome. The most common, type I, has a good prognosis and in our studies it appeared statistically most often. Although postnatal CT is the most reliable examination method for confirming the presence of CCAM, one should remember that the histopathological findings are essential for making the final diagnosis.

The authors declare no conflict of interest.

\section{References}

1. Stocker JT. Congenital pulmonary airway malformation: A new name and an expanded classification of congenital cystic adenomatoid malformation of the lung. Histopathol 2002; 41: 424-431.

2. Lau CT, Kan A, Shek N, et al. Is congenital pulmonary airway malformation really a rare disease? Result of a prospective registry with universal antenatal screening program. Pediatr Surg Int 2017; 33: 105-108.

3. Hong C, Deng H, Li M, et al. Gene expression profiling reveals differential patterns between microcystic congenital cystic adenomatoid malformation and congenital lobar emphysema. Early Hum Dev 2019; 128: 77-80.

4. Chong Y, Rhee YJ, Han SJ, et al. Life-threatening congenital cystic adenomatoid malformation in the premature neonate. Korean J Thorac Cardiovasc Surg 2016; 49: 210-213.

5. Criss CN, Musili N, Matusko N, et al. Asymptomatic congenital lung malformations: is nonoperative management a viable alternative? J Pediatr Surg 2018; 53: 1092-1097.

6. Kantor N, Wayne C, Nasr A. Symptom development in originally asymptomatic CPAM diagnosed prenatally: a systematic review. Pediatr Surg Int 2018; 34: 613-620.

7. Kagawa H, Miki K, Miki M, et al. Congenital cystic adenomatoid malformation in adults detected after infection. Respirol Case Rep 2018; 6: e00364.

8. Abu Omar M, Tylski E, Abu Ghanimeh M, Gohar A. Congenital pulmonary airway malformation (CPAM) with initial presentation in an adult: a rare presentation of a rare disease. BMJ Case Rep 2016; 2016: bcr2016216957.

9. Casagrande A, Pederiva F. Association between congenital lung malformations and lung tumors in children and adults: a systematic review. J Thorac Oncol 2016; 11: 1837-1845.

10. Seear M, Townsend J, Hoepker A, et al. A review of congenital lung malformations with a simplified classification system for clinical and research use. Pediatr Surg Int 2017; 33: 657-664.

11. Durell J, Lakhoo K. Congenital cystic lesions of the lung. Early Hum Dev 2014; 90: 935-939.
12. Japanese Study Group of Pediatric Chest Surgery, Kuroda T, Nishijima E, Maeda K, et al. Perinatal features of congenital cystic lung diseases: results of a nationwide multicentric study in Japan. Pediatr Surg Int 2016; 32: 827-831.

13. Leblanc C, Baron M, Desselas E, et al. Congenital pulmonary airway malformations: state-of-the-art review for pediatrician's use. Eur J Pediatr 2017; 176: 1559-1571.

\section{Address for correspondence}

\section{Damian Młynarski}

Department of Pathology

University Children's Hospital of Krakow

Krakow, Poland

e-mail: d.k.mlynarski@gmail.com 